\title{
Indonesian Throughflow in an eddy-resolving ocean model
}

\author{
FENG Xue ${ }^{1,2}$, LIU HaiLong ${ }^{3 *}$, WANG FuChang ${ }^{3}$, YU YongQiang $^{3}$ \& YUAN DongLiang ${ }^{1}$ \\ ${ }^{1}$ Key Laboratory of Ocean Circulation and Waves, Institute of Oceanology, Chinese Academy of Sciences, Qingdao 266071, China; \\ ${ }^{2}$ University of Chinese Academy of Sciences, Beijing 100049, China; \\ ${ }^{3}$ State Key Laboratory of Numerical Modeling for Atmospheric Sciences and Geophysical Fluid Dynamics, Institute of Atmospheric Physics, \\ Chinese Academy of Sciences, Beijing 100029, China
}

Received March 1, 2013; accepted April 26, 2013; published online July 24, 2013

\begin{abstract}
The performance of the eddy-resolving LICOM2.0 in simulating the Indonesian Throughflow has been evaluated against the INSTANT data in the present study. The mean vertical structures of the along strait velocities are simulated well in LICOM2.0, but the large velocities at the bottom of the Lifamatola Passage and the Timor Passage cannot be reproduced by LICOM2.0. The causes are considered to be both the errors in the topography and the tidal mixing at the bottom. Despite several biases in the mean velocities, the mean inflow and outflow volume transports in LICOM2.0 are almost identical to the INSTANT data. Compared with the lower resolution LICOM, the most significant improvement is the better simulation of the partitions of the inflow and outflow transports in individual straits. The outflow for low-resolution LICOM is mainly through the Ombai and Lombok Strait, whereas that for LICOM2.0 is mainly through the Timor Passage. The variability of the vertical structure of velocities and the volume transport are also investigated. LICOM2.0 overestimates the magnitude of the upper-layer currents and the amplitude of the variation. We also found that the largest correlation coefficient occurs in the shallowest strait, the Lombok, whereas the lowest occurs in the Timor Passage, especially in the upper layer. The latter may be caused by the unrealistic transport through the Torres Strait in LICOM2.0.
\end{abstract}

Indonesian Throughflow, INSTANT, eddy-resolving ocean model, LICOM2.0, volume transport

Citation: Feng X, Liu H L, Wang F C, et al. Indonesian Throughflow in an eddy-resolving ocean model. Chin Sci Bull, 2013, 58: 4504-4514, doi: $10.1007 / \mathrm{s} 11434-013-5988-7$

The Indonesian Throughflow (ITF), which was first mentioned by Wyrtki [1], is the current system connecting the tropical Pacific Ocean and Indian Ocean through the Indonesian Seas. Existing studies have shown that the ITF plays an important role in the volume, heat and salinity exchange between the Indian and Pacific Ocean on timescales from intraseasonal to interannual [2-4]. The ITF also has significant effects on the tropic climate [5,6]. As part of the lowlatitude western boundary current (LLWBC), the ITF has a close relationship with the western boundary current system and the South China Sea Throughflow [7,8]. However, the lack of sustained direct measurements limits our understanding of the ITF to a great extent. Before 2000, knowledge regarding the ITF was limited. The magnitude of the annual

*Corresponding author (email: lhl@lasg.iap.ac.cn) mean transport of the ITF is believed to be between 0 to $30 \mathrm{~Sv}$ [2] as controlled by the wind over the Southern Pacific Ocean based on the Island Rule [9]. Evidence of variability on the seasonal and interannual time-scales has also been discussed [3], but the characteristics of this variability are not clearly known without the long-term monitoring of the major straits. Recently, an international program, the International Nusantara Stratification and Transport (INSTANT), conducted a 3-year-long study from 2004 to 2006 in the five major straits or passages in the Indonesian Seas [10]. These measurements of the velocities, temperatures and salinities not only help us to understand the ITF but also provide an excellent observational reference for the evaluation of numerical models.

Because of the lack of systematic observations, numerical ocean models have been used effectively to estimate the 
mean circulation [11-13], to understand the physical processes [14] and to study the effects of the ITF on the climate $[5,6]$. However, to realistically resolve the narrow straits or passages in the Indonesian Seas, relatively high horizontal resolution is required. Moreover, because the ITF is believed to be part of the thermohaline circulation, a model with global coverage is also required. Both the high resolution and the global domain lead to extremely large computational resources and therefore cost. Alternatively, highresolution ocean general circulation models have been used to study the ITF $[11-13,15]$. For now, the ITF has become an essential metric for high-resolution model evaluation, and model validation is an indispensable step before using any model to study the mechanism of the ITF.

Gordon and McClean [11] found that North Pacific water is well simulated in the Makassar Strait in a $1 / 6^{\circ}$ global ocean model against the Arlindo CTD data (a joint oceanographic research endeavor of Indonesia and the United States), although the sill in the strait is shallower than that observed. However, the water of the eastern route of the ITF is too salty. The model also produces a weak volume transport from the Pacific to the Indian Ocean. Liu et al. [12] evaluated an eddy-permitting ocean model $\left(1 / 2^{\circ}\right)$, the LASG/IAP Climate system Ocean Model version 1.0 (LICOM1.0) [16], for simulation of the ITF. This model is also the previous version of the model in this study. By using the XBT data from the IX1 section, the simulated annual mean volume transport and its seasonal and interannual variability could be carefully investigated. The authors found that the partition of the volume transport in outgoing straits has significant biases, although the net transport was well simulated. Recently, a $1 / 12^{\circ}$ global version of the HYbrid Coordinate Ocean Model (HYCOM) was compared with the INSTANT data in the vertical structure of the along-channel velocities, the seasonal variability and interannual variability [13]. Although the resolution is the highest that can be expected in the climate research, shortcomings still exist, such as incorrect partitioning between the western and eastern routes in HYCOM, etc.

Recently, an eddy-resolving model was developed in LASG based on the early version of LICOM. A 20-year experiment has been conducted forced by the daily mean COREs heat and freshwater data and the QuikSCAT surface wind stresses. The purpose of the present study is to evaluate the simulation of the ITF in this version of LICOM by using the INSTANT dataset. Two questions will be addressed: to what extent could the ITF be represented in an eddy-resolving model; and how may a high resolution ocean model be superior to a coarse resolution model? With these two questions in mind, a baseline comparison of the vertical structure of velocity and the volume transport with the INSTANT dataset was performed to validate the eddy-resolving model. Because the array of the moorings is limited to the key straits (passages) of the ITF and because the shallow Torres Strait and Karimata Strait contribute less to the total transport, our validation also mainly focused on the five straits of the INSTANT program.

\section{Model, experiment and observation}

\subsection{Model description and experiment}

Based on the LASG/IAP Climate system Ocean Model version 2.0 (LICOM2.0) [17], a quasi-global (excluding the Arctic Ocean) eddy-resolving OGCM is built in LASG. The updates and improvements include the following: (1) The horizontal grids are increased to $1 / 10^{\circ}$. (2) The vertical layers are increased to 55 layers. The thickness of the first layer is $5 \mathrm{~m}$. The upper $300 \mathrm{~m}$ has 36 uneven layers, and the mean thickness is less than $10 \mathrm{~m}$. (3) The barotropic and baroclinic split methods are improved. (4) The parallel domain partition is changed from a one-dimensional (1D) Message Passing Interface (MPI) meridional split to a mixed twodimensional (2D) MPI and Open MP. The Open MP parallel algorithm is optimized.

Additional changes include the following: (1) The model domain is from $66^{\circ} \mathrm{N}-79^{\circ} \mathrm{S}$, and thus, the Arctic Ocean is excluded. (2) Biharmonic viscosity and diffusivity schemes are used at the horizontal directions in the equations of momentums and tracers (temperature and salinity), respectively. Meanwhile, the parameterization of mesoscale eddies from Gent and McWilliams [18] is turned off in the equations of tracers.

The eddy-resolving OGCM is spun up for 12 years from zero velocity, initialized from the observed temperature and salinity from the World Ocean Atlas 2005 (WOA05) [19,20] and forced by the climatological monthly wind stress and heat fluxes. The forcing data are from the Ocean Model Intercomparison Project (OMIP) [21], which is derived from ERA15 reanalysis data [22]. In addition, the simulated sea surface salinity (SSS) is restored to the climatological monthly SSS, also from WOA05 [20]. Because the northern open boundary is set at $66^{\circ} \mathrm{N}$, the simulated temperature and salinity are restored to the climatological monthly temperature and salinity from WOA05, whereas the solid wall boundary condition is used for velocity.

After the 12-year spin-up numerical simulations, the eddyresolving OGCM is integrated for an additional 8-year period starting from the end of the 12th year of the spin-up simulation. The model is forced by the daily QuikSCAT wind stress [23] from 2000-2007 and by surface heat and freshwater fluxes derived from COREs [24] during the same period. The detailed algorithm to calculate the turbulent surface fluxes can be found in Large and Yeager [24]. Because the sea ice model is not included in LICOM2.0, the sea ice concentration from the Hadley dataset [25] is used to calculate the surface fluxes. If the temperature of the seawater is below the freezing point $\left(-1.8^{\circ} \mathrm{C}\right)$, the temperature is restored to $-1.8^{\circ} \mathrm{C}$. The 8 -year simulations are used for analysis in the present study. To compare with the observa- 
tions, the results of the same periods are chosen to calculate the annual mean and the "climatology" values.

The basic performance of high resolution LICOM2.0 has been evaluated by $\mathrm{Yu}$ et al. [26]. The model not only better simulates the spatial-temporal features of mesoscale eddies and the paths and positions of western boundary currents than the previous version but also reproduces the large meander of the Kuroshio Current and its interannual variability. The complex structures of equatorial Pacific currents and currents in the coastal ocean of China are also better captured due to the increased horizontal and vertical resolution.

It is well known that the land-sea distributions and topography are extremely complex in the Indonesian Seas. The ability of the model to depict the topography of these passages or straits, therefore, determines the ability of the model to simulate the circulation and transports in this region to a great extent. The model topography of LICOM2.0 is derived from a 5-minute topography, the Digital Bathymetric Data Base 5-minute (DBDB5) from the U.S. Naval Oceanographic Office (gcmd.nasa.gov/records/GCMD_DBDB5.html). Table 1 lists the observational and modeling depths of 10 key locations in this region along with the corresponding literature [4,27-30] from which the observational values come. The locations are also marked by solid red triangles in Figure 1. For locations greater than $25.5 \mathrm{~m}$ (5 model layers, which is also the minimum depth of the water column in LICOM2.0), the depths of the passages are underestimated by $5 \%-30 \%$, except the Alor Strait, which is overestimated. The largest error occurs at the western end of the Timor Passage. The observational depth is $1890 \mathrm{~m}$ in Sprintall et al. [4] and approximately $700 \mathrm{~m}$ shallower in LICOM2.0. This error is also possibly the reason that the currents across the Timor passage are not well simulated. For locations with depths less than $25.5 \mathrm{~m}$, such as the Torres Strait and the Karimata Strait, the depths of the straits are overestimated.

\subsection{INSTANT dataset}

Although a number of measurements in the Indonesian Seas have been undertaken since the 1980s [11,28,31-36], the data are all of limited duration and locations. Most importantly, these observations have been conducted at different times. Thus, historical data cannot provide an integral view of the ITF and are not suitable to validate numerical models. A multi-national program, the International Nusantara Stratification and Transport (INSTANT), was conducted from December 2003/January 2004 to November/December 2006 [37]. The hollow triangles in Figure 1 represent the locations of 11 moorings displaced in two inflow straits (the Makassar Strait and the Lifamatola Passage) and three outflow straits (the Lombok Strait, the Ombai Strait and the Timor Passage). The locations, periods and numbers of moorings in the five straits are also listed in Table 2. The full-depth velocity, salinity and temperature were first simultaneously measured for a 3-year-long period [10].

Observations of different passages or straits have been documented in separate papers, such as Gordon et al. [38] for the Makassar Strait, Van Aken et al. [39] for the Lifamatola Passage and Sprintall et al. [4] for the three outflow passages. The INSTANT dataset provides an opportunity to resolve intraseasonal to interannual variability in the ITF, in the vertical structure of the transport and the volume budget of the Indonesian Seas. To evaluate the large-scale general circulation, the monthly mean velocities derived from the original two-minute mean measurements by the 11 moorings are used in the present study.

The velocity data set from each mooring is first averaged to a time step of 1 hour and then vertically interpolated at $10 \mathrm{~m}$ intervals in the upper $350 \mathrm{~m}$ and $100 \mathrm{~m}$ intervals below $400 \mathrm{~m}$ at each time step. The ADCPs and most current meters have pressure sensors, and the depths of those that do not are calculated from the neighboring sensor. Significant gaps occur in the velocity time series for Lombok West, Timor Sill and Timor Ashmore [4]. Therefore, we choose a mean state strait structure by averaging the hourly data of all the moorings in a definite strait to evaluate the velocity structure and the current variability, and a data gap of one mooring could not significantly affect the mean structure.

The volume transport data at the three outflow passages are adapted from Sprintall et al. [4] (downloaded from the home page of INSTANT). As to the Makassar Strait and

Table 1 The depths of key straits in the Indonesian Seas for observation and LICOM2.0 a)

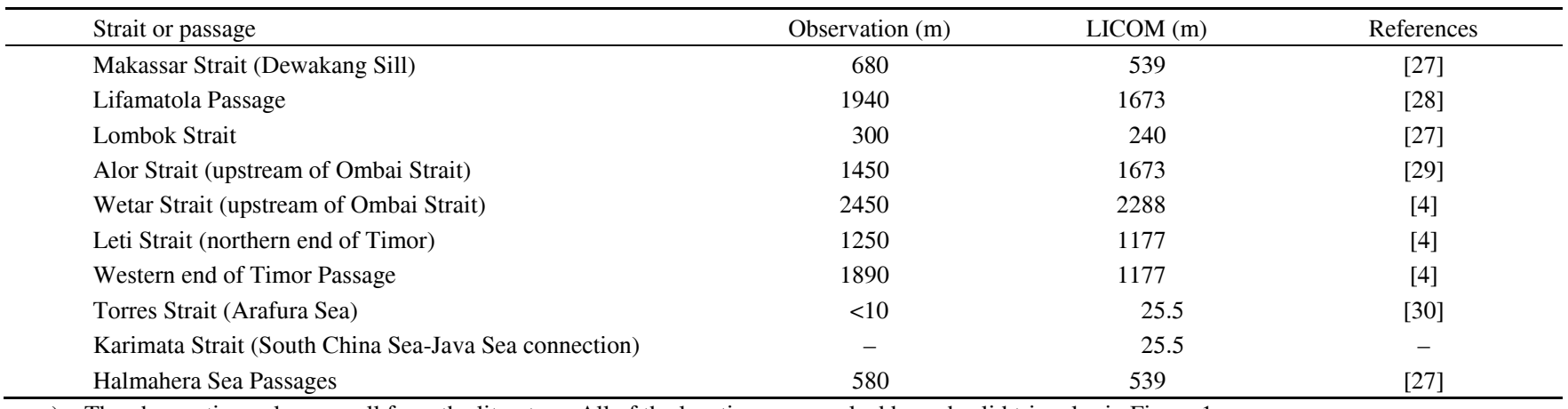

a) The observation values are all from the literature. All of the locations are marked by red solid triangles in Figure 1. 

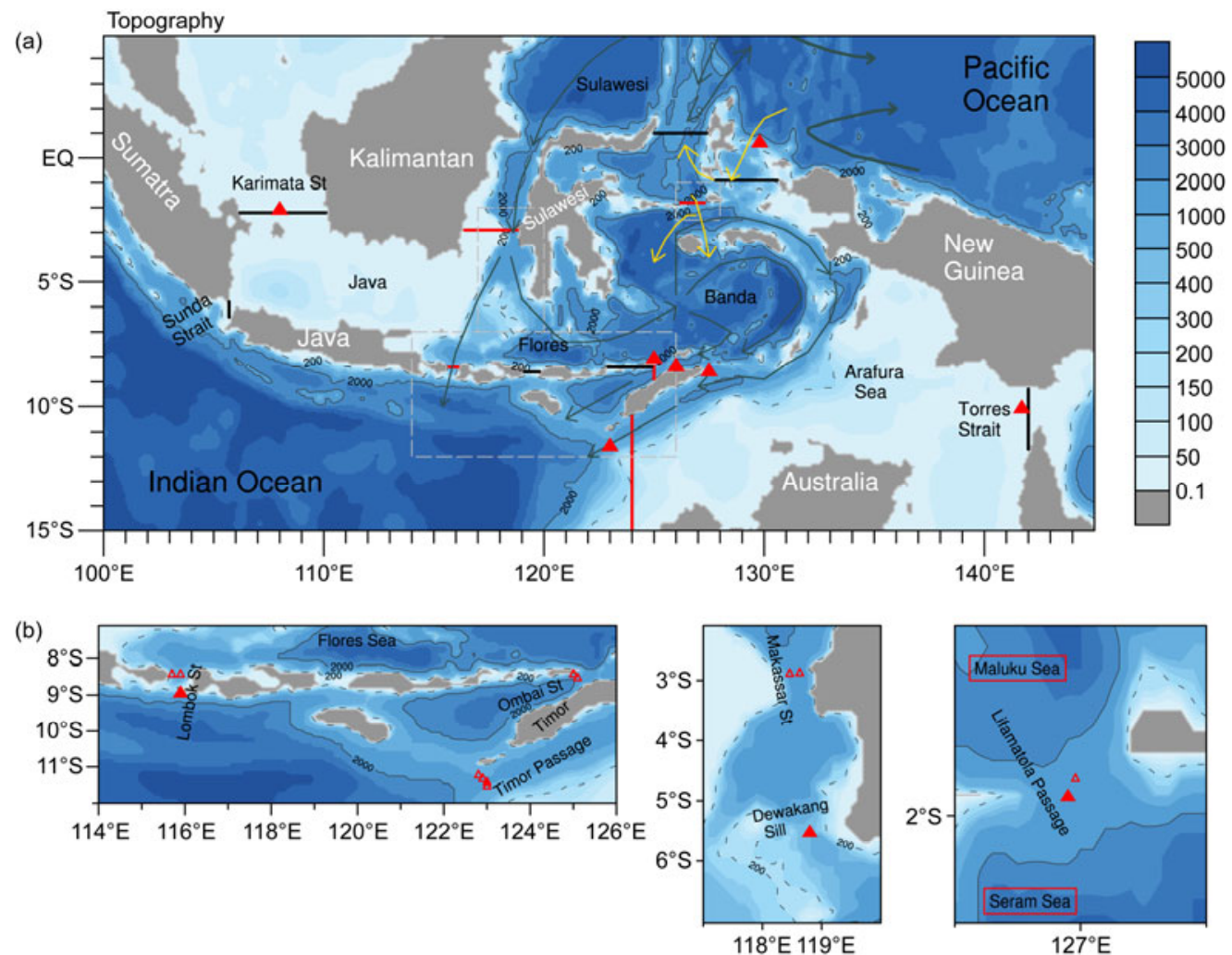

Figure 1 The topography in LICOM2.0 (Units: $\mathrm{m}$ ). The 200 and $2000 \mathrm{~m}$ isobaths are shown by dashed lines and solid lines. The red solid triangles indicate the locations for which the depths have been observed (Table 1). The red hollow triangles indicate the observation sites of INSTANT (Table 3). The red and black lines represent the sections for which we compute the volume transports for LICOM2.0. The red lines represent locations that have been observed during INSTANT, whereas the black lines indicate locations that were not observed. The route of the ITF is also schematically shown following Gordon et al. [38].

Table 2 Detailed information regarding INSTANT moorings in the five straits of the Indonesian Seas

\begin{tabular}{|c|c|c|c|c|}
\hline Strait or passage & Number of mooring & Location & Depth (m) & Period \\
\hline \multirow{2}{*}{ Makassar Strait } & \multirow{2}{*}{2} & $2^{\circ} 51.9^{\prime} \mathrm{S}, 118^{\circ} 27.3^{\prime} \mathrm{E}$ & 2147 & 18 Jan 2004-27 Nov 2006 \\
\hline & & $2^{\circ} 51.5^{\prime} \mathrm{S}, 118^{\circ} 37.7^{\prime} \mathrm{E}$ & 1613 & 18 Jan 2004-27 Nov 2006 \\
\hline Lifamatola Passage & 1 & $1^{\circ} 49.1^{\prime} \mathrm{S}, 126^{\circ} 57.8^{\prime} \mathrm{E}$ & 2019 & 26 Jan 2004-4 Dec 2006 \\
\hline \multirow{2}{*}{ Lombok Strait } & \multirow{2}{*}{2} & $8^{\circ} 26.4^{\prime} \mathrm{S}, 115^{\circ} 45.6^{\prime} \mathrm{E}$ & 921 & 9 Jan 2004-15 Jun 2005 \\
\hline & & $8^{\circ} 24.1^{\prime} \mathrm{S}, 115^{\circ} 53.9^{\prime} \mathrm{E}$ & 1144 & 10 Jan 2004-16 Dec 2006 \\
\hline Ombai Strait & 2 & $8^{\circ} 24.1^{\prime} \mathrm{S}, 125^{\circ} 0.2^{\prime} \mathrm{E}$ & 1329 & 4 Jan 2004-6 Dec 2006 \\
\hline \multirow{4}{*}{ Timor Passage } & \multirow{4}{*}{4} & $11^{\circ} 9.8^{\prime} \mathrm{S}, 122^{\circ} 46.8^{\prime} \mathrm{E}$ & 741 & 1 Jan 2004-12 Dec 2006 \\
\hline & & $11^{\circ} 16.5^{\prime} \mathrm{S}, 122^{\circ} 51.9^{\prime} \mathrm{E}$ & 1890 & 31 Dec 2003-12 Dec 2006 \\
\hline & & $11^{\circ} 22.1^{\prime} \mathrm{S}, 122^{\circ} 57.6^{\prime} \mathrm{E}$ & 1386 & 30 Dec 2003-12 Dec 2006 \\
\hline & & $11^{\circ} 31.7^{\prime} \mathrm{S}, 122^{\circ} 58.4^{\prime} \mathrm{E}$ & 902 & 30 Dec 2003-12 Dec 2006 \\
\hline
\end{tabular}

Lifamatola Passage, we assume a horizontally homogeneous flow through these two straits. Two mooring points in the Makassar Strait are laterally interpolated to the sidewalls, and the single observation point in the Lifamatola Passage is representative of the entire section. Subsequently, the volume transport is calculated by integrating the gridded velocity from top to bottom. In addition, the Lifamatola volume transport used in this study is integrated from $1250 \mathrm{~m}$ to the bottom because the velocity below this depth is well resolved without interruptions.

\section{Results}

\subsection{Velocities}

The vertical structures of transport and velocity in the main ITF channels, their variability and how ENSO-associated climate signals can influence them have recently been extensively studied $[4,40,41]$. To examine the simulated velocity structures and variability in the five principle straits, the mean meridional velocity (in the Makassar Strait, Lifamatola Passage and Lombok Strait) and zonal velocity (in 
Ombai Strait and Timor Passage) are compared between the LICOM2.0 monthly mean output data and the INSTANT observations. Figure 2 shows the annual, February and August mean velocities of the five straits. We average the mooring measurements in each strait if there are more than one mooring. The model data are first interpolated to the mooring locations and then averaged, as with the observations.

The velocities in the Makassar Strait are thermocline intensified with a maximum southward velocity of $0.6 \mathrm{~m} / \mathrm{s}$ near $150 \mathrm{~m}$ (Figure 2a1). This type of vertical structure is believed to be due to the low-order baroclinic modes, which tend to cancel the barotropic response at depth [42]. The vertical profile of the meridional velocity is well simulated in LICOM2.0 except the slightly larger southward maximum below the surface. In INSTANT, the velocities in the upper $150 \mathrm{~m}$ have significant seasonal variability, with weak currents in boreal winter and strong currents in boreal summer, whereas below the surface layer, the variability is weak. LICOM2.0 greatly overestimates the seasonal variability in the surface layer, especially in August. The simulated surface southward velocity can reach $0.9 \mathrm{~m} / \mathrm{s}$, whereas the observed velocity is only $0.3 \mathrm{~m} / \mathrm{s}$, which also causes the large southward current in the annual mean in LICOM2.0.

In contrast, the flow through the Lifamatola Passage is characterized by bottom intensification (Figure 2b1). The exchange of Pacific water with Indonesian Seas mainly occurs in Makassar Strait. However, the Dewakang Sill, at the southern end of Makassar Strait, is only $680 \mathrm{~m}$ in depth. As a result, Lifamatola Passage becomes the pathway for deep ventilation between the Pacific and Banda Sea. Below $1200 \mathrm{~m}$, the velocities increase with depth. A meridional velocity of $0.25 \mathrm{~m} / \mathrm{s}$ can be found at the bottom. LICOM 2.0 simulates a completely different profile: the large southward occurs between 400 and $1300 \mathrm{~m}$; below $1300 \mathrm{~m}$ the velocity quickly decreases to zero with depth. The strong (weak) southward currents appear in February (August). Because there is no observation above $300 \mathrm{~m}$, we cannot evaluate the simulation at these depths. Metzger et al. [13] reported that the $1 / 12^{\circ}$ HYCOM can reproduce the deep overflow well. There are two striking difference between LICOM and HYCOM: first is the vertical coordinate, $\mathrm{z}$ coordinate for LICOM2.0 and a hybrid coordinate for HYCOM; second is the tidal mixing process, which is considered in HYCOM and do not considered in LICOM. Aside from the topography issue mentioned in the second section, the tidal mixing process is considered to be a most important physical process in this region. The biases of the velocity profile in LICOM2, therefore, may partly relate to the missing the tidal mixing process.

The Lombok Strait is the shallowest strait among the five straits. The strait is also surface-trapped, similarly to the Makassar Strait. The largest velocity occurs above $100 \mathrm{~m}$ and gradually decreases with depth. The simulated velocity profile is the same as that of the observations but with a slightly smaller magnitude below $100 \mathrm{~m}$ (Figure 2c1) because of the greatly reduced velocity during the boreal winter. In February, the simulated surface currents even reverse northward, which cannot be found in the INSTANT data.

The Ombai Strait is an important exit of the ITF. In INSTANT data, the large westward flow is in the upper $300 \mathrm{~m}$ and reduces below the surface layer to zero with depth (Figure 2d1). The shape of the profile is well simulated by LICOM2.0 but with almost doubled magnitude in the upper $300 \mathrm{~m}$. There is also a second westward flow maximum near $900 \mathrm{~m}$ in LICOM2.0 that cannot be found in the observation. The seasonal variability primarily occurs in the upper layer, with a weak westward current in February and strong westward currents in August (Figure 2d2 and $2 \mathrm{~d} 3$ ). This variability is related to the South Java Current. LICOM2.0 reproduces the correct phase of the seasonal variability of the surface currents but overestimates the magnitude, as in the Lombok Strait. In the boreal winter, the simulated surface currents even reverse, but the annual mean value is still a strong westward flow. Near $200 \mathrm{~m}$, the westward current has weak seasonal differences in both the observation and the simulation, but the currents are overestimated for the entire year in LICOM2.0.

Timor Passage is a narrow trench between the Timor land and Australian continental shelf and is the deepest strait among the five straits. The velocities in this passage show both a surface-trapped feature and a bottom-intensified feature. The maximum westward currents (approximately $0.3 \mathrm{~m} / \mathrm{s}$ ) appear near $100 \mathrm{~m}$ and gradually decrease to less than $0.1 \mathrm{~m} / \mathrm{s}$ between 400 and $1600 \mathrm{~m}$. The eastward flow can be found below $1600 \mathrm{~m}$, which means that Indian Ocean water enters the Indonesian Seas at bottom layer in the Timor Passage. Comparison between the annual mean and the monthly mean results indicates that the eastward currents mainly occur in the boreal summer. The surfacetrapped feature is well simulated by LICOM2.0, but because the depth of the Timor Passage is much shallower than that in the observation, the bottom reverse cannot be simulated in LICOM2.0. This error may also possibly occur due to missing tidal mixing in LICOM2.0, as in the Lifamatola Passage.

In summary, LICOM2.0 simulates the velocity profiles in the five straits fairly well, especially in the Makassar Strait, the Lombok Strait and the Timor Passage. The large biases mainly occur at the bottom of the Lifamatola Passage and the Timor Passage. Aside from the biases in the topography of LICOM2.0, the missing tidal mixing in LICOM2.0 may also be one of the important causes of the bottom biases. For the seasonal variability, the model captures the phase well: the strong currents from the Pacific to the Indian Ocean in the boreal summer and the weak currents in the boreal winter, though the amplitudes of the simulated currents are much overestimated. The reasons for the biases are not obvious and need further investigation.

The INSTANT data cover a three-year long period, so 

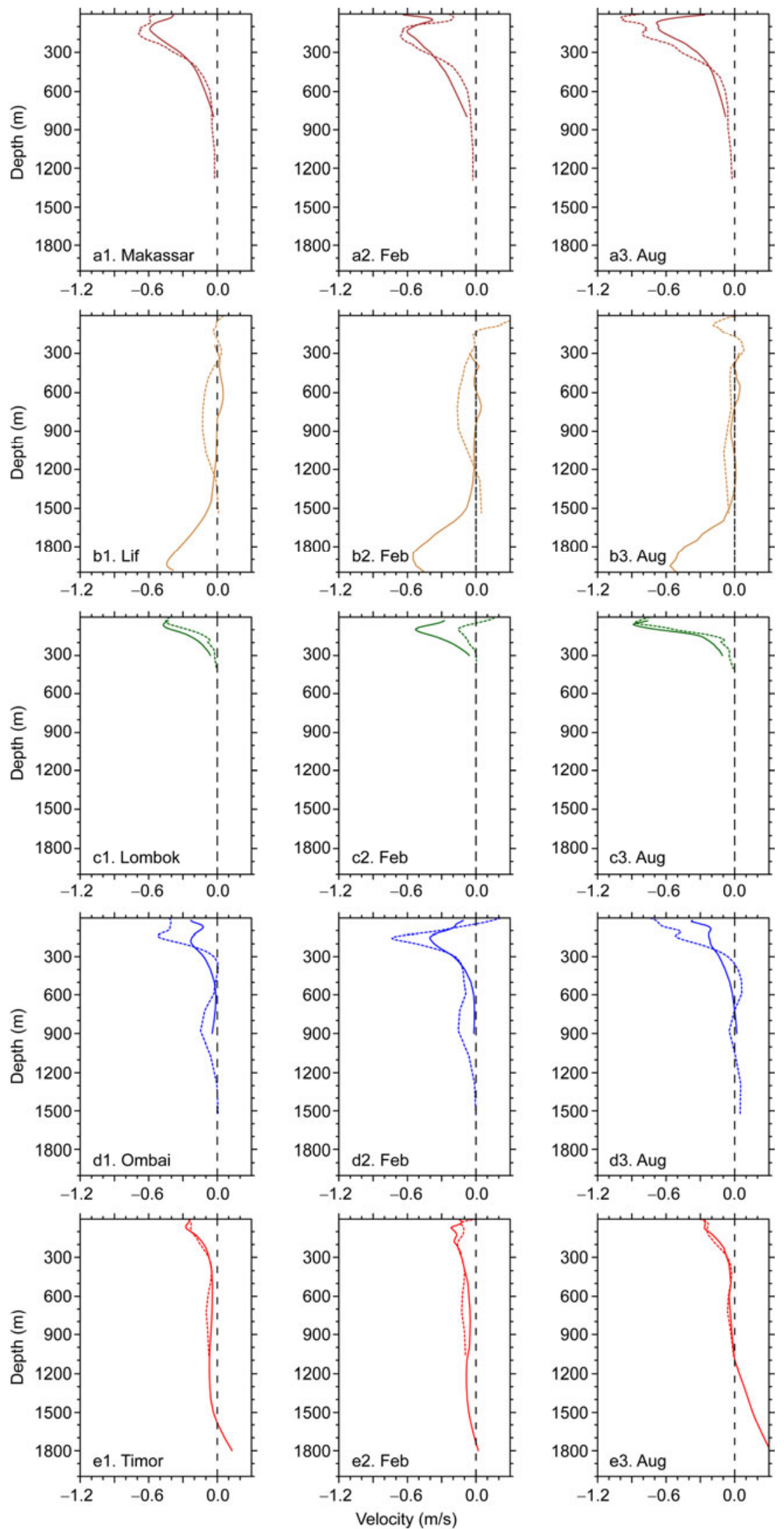

Figure 2 Vertical structures of the mean velocity at (a) the Makassar Strait, (b) the Lifamatola Passage, (c) the Lombok Strait, (d) the Ombai Strait, (e) the Timor Passage for INSTANT (solid) and LICOM2.0 (dash). The left, middle and right panels represent annual, February and August mean profiles, respectively. The five straits are represented with different colors: Makassar Strait (brown), Lifamatola Passage (orange), Lombok Strait (green), Ombai Strait (blue) and Timor Passage (red). 
we also present the entire time serials in this study to evaluate the long-term variability. Figure 3 shows the observed and simulated currents at 50, 150, 350 and $750 \mathrm{~m}$ from 2004 to 2006, respectively. Because strong bias and missing data are found in these layers in the Lifamatola Passage, only four straits are shown. To evaluate the model more qualitatively, the mean values and the standard deviations for both INSTANT and LICOM2.0 are shown in Table 3, and the correlation coefficients between the observation and the simulation are presented in Figure 3 with different colors for different straits.

At first glance, the amplitudes of the variability decrease with the depth. This trend can also be found in the simulation, but the amplitudes of the model are much larger than that of the INSTANT data, especially in the Makassar Strait, in which the model simulates much larger southward currents in the boreal summer. LICOM2.0 has simulated strong currents and variability in the upper two layers in almost all straits, except the Timor Passage (Figure 3 and Table 3). The large correlation coefficients indicate that the variability is also fairly well simulated in the three straits (the Ma-
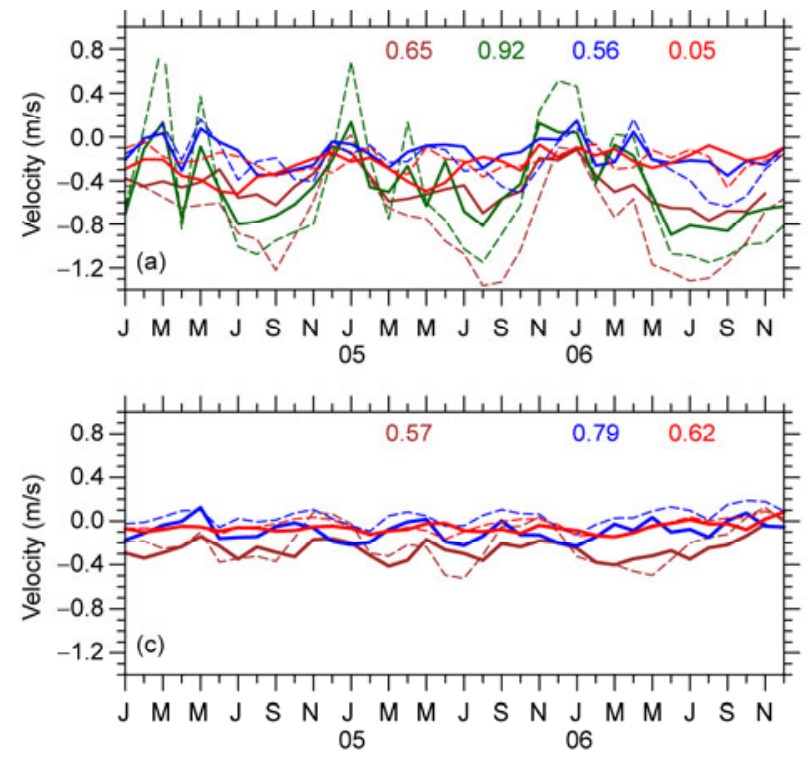

Figure 3 The monthly mean velocities for INSTANT (solid) and LICOM2.0 (dash) at (a) $50 \mathrm{~m}$, (b) $150 \mathrm{~m}$, (c) $350 \mathrm{~m}$, (d) $750 \mathrm{~m}$ velocity at four straits, the Makassar Strait (brown), Lombok Strait (green), Ombai Strait (blue) and Timor Passage (red). Numbers in the top are correlation coefficients between INSTANT and LICOM2.0 with seasonal signal removed.

Table 3 The period mean and the standard deviation of the monthly mean velocity for both INSTANT and LICOM2.0 at 50, 150,350 and $750 \mathrm{~m}$

\begin{tabular}{|c|c|c|c|c|c|}
\hline Strait or passage & & $50 \mathrm{~m}$ & $150 \mathrm{~m}$ & $350 \mathrm{~m}$ & $750 \mathrm{~m}$ \\
\hline \multirow[t]{2}{*}{ Makassar Strait } & Obs. & $-0.46 \pm 0.17$ & $-0.56 \pm 0.08$ & $-0.26 \pm 0.09$ & $-0.05 \pm 0.06$ \\
\hline & Model & $-0.75 \pm 0.37$ & $-0.81 \pm 0.10$ & $-0.21 \pm 0.18$ & $-0.04 \pm 0.04$ \\
\hline \multirow[t]{2}{*}{ Lombok Strait } & Obs. & $-0.46 \pm 0.32$ & $-0.21 \pm 0.10$ & - & - \\
\hline & Model & $-0.49 \pm 0.59$ & $-0.25 \pm 0.15$ & - & - \\
\hline \multirow[t]{2}{*}{ Ombai Strait } & Obs. & $-0.15 \pm 0.13$ & $-0.22 \pm 0.11$ & $-0.09 \pm 0.09$ & $-0.02 \pm 0.08$ \\
\hline & Model & $-0.22 \pm 0.20$ & $-0.43 \pm 0.25$ & $0.04 \pm 0.07$ & $-0.06 \pm 0.07$ \\
\hline \multirow[t]{2}{*}{ Timor Passage } & Obs. & $-0.25 \pm 0.12$ & $-0.15 \pm 0.05$ & $-0.06 \pm 0.04$ & $-0.04 \pm 0.04$ \\
\hline & Model & $-0.22 \pm 0.10$ & $-0.17 \pm 0.06$ & $-0.04 \pm 0.06$ & $-0.09 \pm 0.05$ \\
\hline
\end{tabular}

kassar Strait, the Lombok Strait and the Ombai Strait), while there is almost no correlation between the INSTANT data and the LICOM2.0 simulation in the first two layers of Timor Passage. It is interesting that the correlation coefficients in the lower layers become large. As we will show below, the transport of the Torres Strait is largely overestimated in LICOM2.0. Therefore, the variability of the surface layer of the Timor Passage may be dominated by the signals propagating from the tropic Pacific Ocean through the Torres Strait instead of the local wind and the propagation from the Banda Sea as in the observation.

\subsection{Volume transport}

Aside from the velocity itself, volume transport is also a common metric to evaluate the ITF. The mean transport between the Pacific Ocean and the Indian Ocean was once thought to be driven by the pressure gradient between the two oceans $[1,43]$. In the early days, the observation values range from 0 to $30 \mathrm{~Sv}$ [2]. During the past $10-15$ years, the volume transport has been believed to be approximately
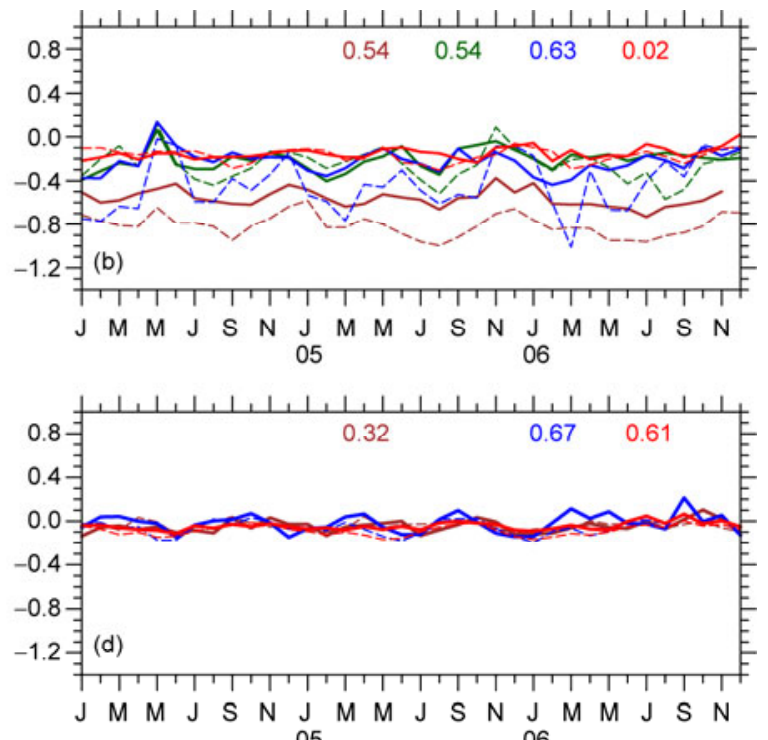

$-0.04 \pm 0.06$

$-0.09 \pm 0.05$ 
10-15 Sv based on both observations [37] and theoretical estimation [9]. The values are thought to have become more reliable as the data quality has improved [44]. The model simulations are also within the range of the observation [11-13]. Table 4 shows the annual mean volume transport for LICOM2.0 and INSTANT observation in the five primary straits. Because of space limitations, the results from LICOM1.0 [12] and HYCOM [13] are not shown. Please refer to [12] and [13] for details.

The sums of the transports of the two inflow straits (the Makassar Strait and Lifamatola Passage) and the three outflow straits (the Lombok Strait, the Ombai Strait and the Timor Passage) are considered to be the total inflow transport and the total outflow transport, respectively. Both the inflow and outflow transports have been well simulated in LICOM2.0. For the inflow transports, there are only $0.1 \mathrm{~Sv}$ different between the simulation and the observation, 14.0 Sv for LICOM2.0 and 14.1 Sv for INSTANT observation. For the outflow transport, both LICOM2.0 and INSTANT are 15.0 $\mathrm{Sv}$. With regard to each individual strait, the Lombok Strait is best simulated, with $-2.7 \mathrm{~Sv}$ for LICOM2.0 and $-2.6 \mathrm{~Sv}$ for INSTANT. The biases of the other four straits are canceled out each other. The transports of the Makassar Strait and the Timor Passage are overestimated, whereas the transports of the Lifamatola Passage and the Ombai Strait are underestimated.

In the coarse or medium resolution models, the most evident bias is the distribution of the total transport in the straits, although the magnitudes of the total transport are well simulated [11,12]. Both Gordon et al. [11] and Liu et al. [12] have shown an extreme large transport (exceeding 30\% of the total outflow transport) through the Lombok Strait, but the INSTANT only observed $17 \%$ of the total outflow transport within the Lombok Strait. So the partition of the outflow transport for LICOM2.0 is greatly improved. The southward transport of Lombok Strait for LICOM2.0 is only $2.7 \mathrm{~Sv}$, which is close to INSTANT value, 2.6 Sv. Furthermore, the ratio of the transport of the Lombok Strait to the total outflow transport for LICOM2.0 is approximately $18 \%$, near the $17 \%$ for INSTANT. Although there is large uncertainty for the Lifamatola Passage in INSTANT, the partition of the inflow straits is also significantly improved. The ratio of the transport through the Makassar Strait against the total incoming transport increases from approximately 60\% (the total volume transport is assumed $12.8 \mathrm{~Sv}$ ) for LICOM1.0 to $77 \%$ for LICOM2.0. HYCOM has the same type of improvement, too. These results indicate that the horizontal resolution is crucial for the partition of the transports.

An approximately $1 \mathrm{~Sv}$ imbalance between inflow and outflow in the INSTANT data and the LICOM2.0 simulation exists. That imbalance inspires us to find the contribution of other pathways to the total ITF, which are excluded from the INSTANT field program. Because there are no simultaneous measurements at the other straits or passages during the INSTANT period, the results from LICOM2.0 are compared with the previous observations and/or the results from HYCOM. The transports through the Karimata Strait, the Maluku Strait, the Halmahera Strait, the Torres Strait and three narrow straits within the Nusa Tenggara Archipelago (the Sunda Strait, the Sape Strait and the Alor Strait) are computed. The former four straits contribute to the inflow transport and the later three to the outflow. The total incoming transport through other straits is $6.4 \mathrm{~Sv}$, and the outgoing transport is $1.8 \mathrm{~Sv}$. Notice that the transport through the Lifamatola Passage is also included in the sum of transport through the Maluku and the Halmahera Strait.

Table 4 The volume transport of five INSTANT straits and seven small straits for INSTANT, LICOM2.0, LICOM1.0 and HYCOM ${ }^{\text {a) }}$

\begin{tabular}{|c|c|c|c|c|c|}
\hline Strait or passage & & $\begin{array}{c}\text { Location } \\
\text { (Latitude/Longitude) }\end{array}$ & $\begin{array}{c}\text { Depth }(\mathrm{m}) \\
\text { Model }\end{array}$ & $\begin{array}{c}\text { INSTANT (Sv) } \\
\text { Mean }(2004 / 2005 / 2006)\end{array}$ & $\begin{array}{c}\text { LICOM2.0 (Sv) } \\
\text { Mean }(2004 / 2005 / 2006)\end{array}$ \\
\hline Makassar Strait & & $2.9^{\circ} \mathrm{S} / 116.4^{\circ}-118.8^{\circ} \mathrm{E}$ & 1673 & $-11.6(-11.3 /-11.6 /-11.8)$ & $-10.8(-9.4 /-10.9 /-12.0)$ \\
\hline Lifamatola Passage & & $1.8^{\circ} \mathrm{S} / 126.2^{\circ}-127.3^{\circ} \mathrm{E}$ & 1966 & $-2.5(-2.1 /-2.6 /-2.7)$ & $-3.2(-2.3 /-4.6 /-2.7)$ \\
\hline Total inflow & & & & -14.1 & -14.0 \\
\hline Lombok Strait & & $8.4^{\circ} \mathrm{S} / 115.6^{\circ}-116.2^{\circ} \mathrm{E}$ & 675 & $-2.6(-2.0 /-2.3 /-3.4)$ & $-2.7(-2.5 /-2.3 /-3.3)$ \\
\hline Ombai Strait & & $8.4^{\circ}-8.9^{\circ} \mathrm{S} / 125^{\circ} \mathrm{E}$ & 2288 & $-4.9(-4.7 /-5.8 /-4.3)$ & $-3.1(-2.8 /-4.1 /-2.5)$ \\
\hline Timor Passage & & $10.4^{\circ}-16.3^{\circ} \mathrm{S} / 124^{\circ} \mathrm{E}$ & 1410 & $-7.5(-7.3 /-7.6 /-7.6)$ & $-9.2(-8.6 /-10.3 /-8.9)$ \\
\hline Total outflow & & & & -15.0 & -15.0 \\
\hline Karimata & & $2.2^{\circ} \mathrm{S} / 106.2^{\circ}-110.1^{\circ} \mathrm{E}$ & 42 & - & -1.1 \\
\hline Maluku & & $1^{\circ} \mathrm{N} / 125^{\circ}-127.4^{\circ} \mathrm{E}$ & 2637 & - & -2.5 \\
\hline Halmahera & & $0.9^{\circ} \mathrm{S} / 127.8^{\circ}-130.6^{\circ} \mathrm{E}$ & 1410 & - & -1.2 \\
\hline Torres & & $9.2^{\circ}-11.9^{\circ} \mathrm{S} / 142^{\circ} \mathrm{E}$ & 25.5 & - & -1.6 \\
\hline Total inflow & & & & - & -6.4 \\
\hline \multirow[t]{3}{*}{$\begin{array}{l}\text { Nusa Tenggara } \\
\text { archipelago }\end{array}$} & Sunda & $5.8^{\circ}-6.4^{\circ} \mathrm{S} / 105.7^{\circ} \mathrm{E}$ & 31 & - & -0.3 \\
\hline & Sape & $8.6^{\circ} \mathrm{S} / 119.1^{\circ}-119.8^{\circ} \mathrm{E}$ & 110 & - & -0.9 \\
\hline & Alor & $8.4^{\circ} \mathrm{S} / 123^{\circ}-125^{\circ} \mathrm{E}$ & 126 & - & -0.6 \\
\hline Total out flow & & & & - & -1.8 \\
\hline
\end{tabular}

a) The locations and depths of the sections at which the volume transports are computed are also shown. Note that the integrated depth of the Lifamatola Passage is from $1250 \mathrm{~m}$ to the bottom for INSTANT. 
Therefore, overall, there is near balance in the Indonesian Seas in LICOM2.0 during 2004-2006, with 17.2 Sv for inflow and $16.8 \mathrm{~Sv}$ for outflow. HYCOM also has an approximately $0.4 \mathrm{~Sv}$ imbalance during that time, which indicates that the $1 \mathrm{~Sv}$ imbalance comes from the other straits, which are not considered in the INSTANT program.

Observation-based transport estimations in Karimata Strait reported by Wyrtki [1] were $4.5 \mathrm{~Sv}$ in winter toward the Java Sea and $3 \mathrm{~Sv}$ in summer toward the South China Sea (SCS). Based on current data from 13 January to 12 February 2008 in Karimata Strait, Fang et al. [45] gave a mean winter volume transport of $3.6 \mathrm{~Sv}$ from SCS to the Indonesian Seas. The annual mean transport is about -0.75 $\mathrm{Sv}$ [1]. The simulation of LICOM2.0, $-1.1 \mathrm{~Sv}$, is close to the observational value. However, the transport through the Torres Strait is much more overestimated in LICOM2.0, just as that for LICOM1.0. The observed annual mean transport is approximately $0.01 \mathrm{~Sv}$ [30], whereas the transport is $1.6 \mathrm{~Sv}$ for both LICOM2.0 and LICOM1.0, which leads to large transport in the Timor Passage and the great effect of Pacific winds on its variability, as mentioned before.

The transports in the Indonesian Seas also have seasonal to interannual time-scale variability. The monthly climatology full-depth transport of the five straits for both the observation and the simulation are shown in Figure 4. The Makassar, Lifamatola and Ombai Strait all show significant semiannual variability in INSTANT data. However, the Makassar Strait displays a different phase from the other two straits: the maximum southward transport occurs in spring and fall. The Lombok Strait and Timor Passage are dominated by the annual cycle. However, LICOM2.0 almost cannot capture the semiannual signal, especially in the Makassar and the Ombai Strait. As Clarke and Liu [46] suggested, the semiannual signal is propagated from the equatorial Indian Ocean. The variability of winds over the tropic Indian Ocean should be investigated further. Another large bias occurs in the Timor Passage. The transport in the boreal spring has been extremely overestimated in LICOM2.0, which is related to the overestimation in the Torres Strait.

The time series of monthly mean transport for the five straits are shown in Figure 5. The correlation coefficients between the observations and the simulations over the INSTANT period are also shown in the figure. It is clear that the model tends to simulate large amplitudes of variability, which is also found in the velocities (Figure 3). Because the measurements of the upper layer have been missing, the amplitude of the transport in the Lifamatola Passage is fairly small in INSTANT. In terms of the variability, the shallowest strait, Lombok, has the best results (0.78). The correlation coefficient of the Timor Passage is the smallest of the straits (0.39), just above the critical value (0.34) of the significant test. The large discrepancies occur during the boreal spring season in Timor Passage, when there are large transports from the tropic Pacific through the Torres Strait. Despite an unrealistic vertical structure and the large am-

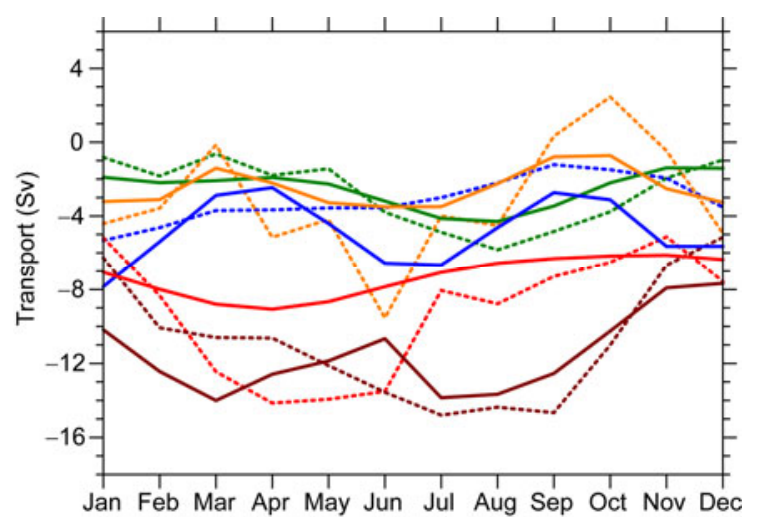

Figure 4 The monthly mean climatology of volume transports for INSTANT (solid) and LICOM2.0 (dash) at the Makassar Strait (brown), Lifamatola Passage (orange), Lombok Strait (green), Ombai Strait (blue) and Timor Passage (red).

plitude simulated in Lifamatola Passage, the phase of interannual oscillation of depth-integrated transport agrees well with observations (Figure 5).

Because 2004-2006 are considered normal years [38], there is no evident large interannual variability in the observed volume transports. However, Gordon et al. [37] reported increasing transport during those three years in the Makassar Strait. That type of trend also can be found in other straits, except the Ombai Strait (Table 4). However, such a trend cannot be found in LICOM2.0, except in the Makassar Strait. What causes the trend and why it cannot be simulated in LICOM2.0 both need further investigation.

\section{Concluding remarks}

In the present study, the performance of the eddy-resolving LICOM2.0 in simulating the Indonesian Throughflow (ITF) has been evaluated against the INSTANT data. The INSTANT program is an international field program that provides the first continual simultaneous observation of the five major pathways of ITF for a 3-year period (2004-2006). In this study, only the velocities and the volume transports are validated.

The three-year mean vertical structures of the along strait velocities are simulated very well in LICOM2.0. The large discrepancies mainly occur in the Lifamatola Passage, in which the bottom-intensify feature cannot be captured by LICOM2.0. The reverse currents at the bottom of the Timor Passage also cannot be found in LICOM2.0. These biases at the bottom layer are close related with the depth of the sill in the two passages. LICOM2.0 tends to underestimate the deep strait or passage. In addition to the topography, the weak bottom currents in LICOM2.0 may be partly due to missing the tidal mixing process, which is believed to be an important mixing process in the Indonesian Seas. Despite some biases in the mean velocities, the mean inflow and outflow volume transports in LICOM2.0 are almost identical 

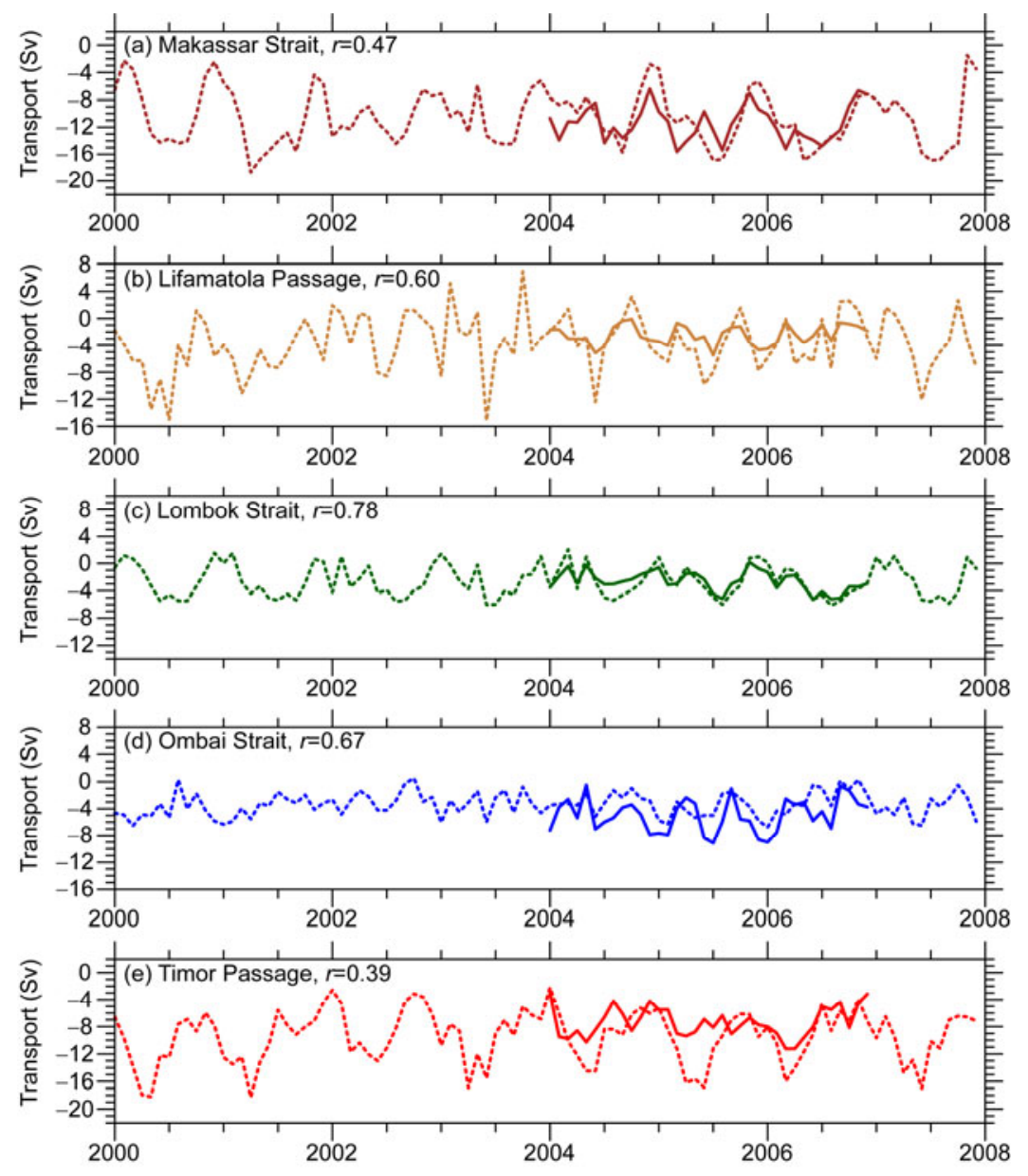

Figure 5 The monthly mean volume transports for INSTANT (solid) and LICOM2.0 (dash) at the Makassar Strait, Lifamatola Passage, Lombok Strait, Ombai Strait and Timor Passage. The correlation coefficients between INSTANT and LICOM2.0 are also shown in each panel.

to the INSTANT data. Because many small straits are excluded from the INSTANT, there is $1 \mathrm{~Sv}$ imbalance between the inflow and outflow transport. The investigation of the transport through other straits also suggests this guess.

The variability of the vertical structure of velocities and the volume transport are also investigated. LICOM2.0 simulates the correct phase of the seasonal cycle: large (small) transport from Pacific to Indian during the boreal summer (winter). However, LICOM2.0 overestimates the magnitude of the surface currents, as well as the amplitude of the seasonal variation. The strong surface currents would lead to large heat transport in LICOM2.0 (not shown), but the reason for the strong surface currents and large amplitude is not clear. In addition, the semiannual signals in the Makassar Strait, the Lifamatola Passage and the Ombai Strait almost cannot be reproduced. There is no evident event in the interannual time scale during this period, but we still show the entire monthly time serial in the present study. Aside from the large amplitude of the variation in LICOM2.0, the shallowest strait, Lombok, is best simulated the monthly variation in LICOM2.0. However, the unrealistic transport through the Torres Strait leads to lowest correlation coefficient in the Timor Passage, especially in the upper $200 \mathrm{~m}$.
Compared with the lower-resolution LICOM1.0 [12], the most significant improvement is the better simulated partitions of the inflow and outflow transports in individual straits. The outflow for LICOM1.0 is mainly through the Ombai and Lombok Strait and through the Timor Passage for LICOM2.0. The latter is close to the INSTANT observation. Although this accuracy in volume distribution is not the only merit of the high resolution, further systematic investigation should be conducted with the lower resolution LICOM1.0.

In the present study, we only evaluated the velocities and volume transports. The temperatures and salinities were also measured in INSTANT. The preliminary analysis shows that the salty south Pacific water below the thermocline in the Banda Sea appears above $400 \mathrm{~m}$, whereas in the observation [11], it can extend to as deep as $700 \mathrm{~m}$ (not shown). This bias may be related to biases in the vertical mixing. The simulated temperature and salinity will also be evaluated in future work.

This work was supported by the National Basic Research Program of China (2010CB951904 and 2013CB956204), the National Natural Science Foundation of China (41275084, 41075059 and 41023002), and the Stra- 
tegic Priority Research Program-Climate Change: Carbon Budget and Related Issues of the Chinese Academy of Sciences (XDA05110302). The experiment has been done on TianHe-1A system.

1 Wyrtki K. Scientific Results of Marine Investigations of the South China Sea and the Gulf of Thailand 1959-1961, Physical oceanography of the Southeast Asian waters, NAGA Report. California: Scripps Institution of Oceanography, 1961. 1-195

2 Godfrey J S. The effect of the Indonesian Throughflow on ocean circulation and heat exchange with the atmosphere: A review. J Geophys Res, 1996, 101: 12217-12237

3 Meyers G. Variation of Indonesian Throughflow and the El NinoSouthern Oscillation. J Geophys Res, 1996, 101: 12255-12263

4 Sprintall J, Wijffels S E, Molcard R, et al. Direct estimates of the Indonesian Throughflow entering the Indian Ocean: 2004-2006. J Geophys Res, 2009, 114: C07001

5 Hirst A C, Godfrey J S. The role of Indonesian Throughflow in a global ocean GCM. J Phys Oceanogr, 1993, 23: 1057-1086

6 Schneider N. The Indonesian Throughflow and the Global Climate System. J Clim, 1998, 11: 676-689

7 Wang W W, Wang D X, Zhou W, et al. Impact of the South China Sea throughflow on the Pacific low-latitude western boundary current: A numerical study for seasonal and interannual time scales. Adv Atmos Sci, 2011, 28: 1367-1376

8 Liu Q Y, Huang R X, Wang D X, et al. Interplay between the Indonesian Throughflow and the Luzon Strait Throughflow. Chin Sci Bull, 2006, 51(supp. II): 50-58

9 Godfrey J S. A Sverdrup model of the depth-integrated flow for the world ocean allowing for Island circulations. Geophys Astrophys Fluid Dyn, 1989, 45: 89-112

10 Sprintall J, Wijffels S E, Gordon A L, et al. INSTANT: A new international array to measure the Indonesian Throughflow. EOS, 2004, 85: 369

11 Gordon A L, McClean J L. Thermohaline stratification of the Indonesian Seas: Model and Observations. J Phys Oceanogr, 1999, 29: 198-216

12 Liu H L, Li W, Zhang X H. Climatology and Variability of the Indonesian Throughflow in an Eddy-permitting Oceanic GCM. Adv Atmos Sci, 2005, 22: 496-508

13 Metzger E J, Hurlburt H E, Xu X, et al. Simulated and observed circulation in the Indonesian Seas: $1 / 12^{\circ}$ global HYCOM and the INSTANT observations. Dyn Atmos Oceans, 2010, 50: 275-300

14 Masumoto Y, Yamagata T. Seasonal variations of the Indonesian Throughflow in a general circulation model. J Geophys Res, 1996, 101: 12287-12293

15 Masumoto Y, Morioka Y, Sasaki H. High-resolution Indian Ocean simulations-Recent advances and issues from OFES. Geophys Monogr Ser, 2008, 177: 199-212

16 Liu H L, Yu Y Q, Li W, et al. Reference Manual of LASG/IAP Climate System Ocean Model (LICOM1.0). The Special Issue of LASG Technical Report (in Chinese). Beijing: Science Press, 2004

17 Liu H L, Lin P F, Yu Y Q, et al. The baseline evaluation of LASG/IAP Climate system Ocean Model (LICOM) version 2. Acta Meteorol Sin, 2012, 26: 318-329

18 Gent P R, McWilliams J C. Isopycnal mixing in ocean circulation models. J Phys Oceanogr, 1990, 20: 150-155

19 Locarnini R A, Mishonov A V, Antonov J I, et al. World Ocean Atlas 2005. Volume 1: Temperature. NOAA Atlas NESDIS 61.Washington D C: U.S. Government Printing Office, 2006

20 Antonov J I, Locarnini R A, Boyer T P, et al. World Ocean Atlas 2005. Volume 2: Salinity. NOAA Atlas NESDIS 62. Washington D C: U.S. Government Printing Office, 2006

21 Röske F. An atlas of surface fluxes based on the ECMWF re-analysisA climatological dataset to force global ocean general circulation models. Germany, Hamburg MPI: Report No. 323, 2001

22 Gibson J K, Coauthor. ERA Description, ECMWF Reanalysis Project Report Series 1, European Center for Medium Range Weather Forecast. UK: Reading, 1997. 66

23 CERSAT-IFREMER. QuikSCAT Scatterometer Mean Wind Field Product. User Manual, C2-MUT-W-03-IF, 2002

24 Large W, Yeager S. Diurnal to Decadal Global Forcing for ocean and Sea-Ice Models: The Data Sets and Flux Climatologies, NCAR/TN460+STR, 2004

25 Rayner N A, Brohan P, Parker D E, et al. Improved analyses of changes and uncertainties in sea surface temperature measured in situ since the mid-nineteenth century: The HadSST2 data set. J Clim, 2006, 19: 446-469

26 Yu Y Q, Liu H L, Lin P F. A quasi-global (1/10) ${ }^{\circ}$ eddy-resolving ocean general circulation model and its preliminary results. Chin Sci Bull, 2012, 57: 3908-3916

27 Gordon A L, Giulivi C F, Ilahude A G. Deep topographic barriers within the Indonesian seas. Deep-Sea Res II, 2003, 50: 2205-2228

28 van Aken H M, Punjana J, Saimima S. Physical aspects of the flushing of the east Indonesian basins. Neth J Sea Res, 1988, 22: 315-339

29 Sprintall J, Wijffels S E, Molcard R, et al. Direct evidence of the South Java Current system in Ombai Strait. Dyn Atmos Oceans, 2010, 50: $140-156$

30 Wolanski E, Rido E, Inoue M. Currents through Torres. J Phys Oceanogr, 1988, 18: 1535-1545

31 Murray S P, Arief D. Throughflow into the Indian Ocean through the Lombok Strait, January 1985-January 1986. Nature, 1988, 333: 444-447

32 Cresswell G, Frische A, Peterson J. Circulation in the Timor Sea. J Geophys Res, 1993, 98: 14379-14389

33 Molcard R, Fieux M, Ilahude A G. The Indo-Pacific Throughflow in the Timor Passage. J Geophys Res, 1996, 101: 12411-12420

34 Molcard R, Fieux M, Syamsudin F. The throughflow within Ombai Strait. Deep-Sea Res, 2001, 48: 1237-1253

35 Luick J L, Cresswell G R. Current measurements in the Maluku Sea. J Geophys Res, 2001, 106: 13953-13958

36 Cresswell G R, Luick J L. Current measurements in the Halmahera Sea. J Geophys Res, 2001, 106: 13945-13951

37 Gordon A L, Sprintall J, van Aken H M, et al. The Indonesian Throughflow during 2004-2006 as observed by the INSTANT program. Dyn Atmos Oceans, 2010, 50: 115-128

38 Gordon A L, Susanto R D, Ffield A, et al. Makassar Strait throughflow, 2004 to 2006. Geophys Res Lett, 2008, 35: L24605

39 van Aken H M, Brodjonegoro I S, Jaya I. The deep-water motion through the Lifamatola Passage and its contribution to the Indonesian Throughflow. Deep-Sea Res, 2009, 56: 1203-1216

40 Hautala S L, Sprintall J, Potemra J T, et al. Velocity structure and transport of the Indonesian throughflow in the major strait restricting flow into the Indian Ocean. J Geophys Res, 2001, 106: 19527-19546

41 Potemra J T, Hautala S L, Sprintall J. Vertical structure of the Indonesian Throughflow in a large-scale model. Deep-Sea Res, 2003, 50: 2143-2161

42 McCreary J, Miyama T, Furue R, et al. Interactions between the Indonesian Throughflow and circulations in the Indian and Pacific Oceans. Prog Oceanogr, 2007, 75: 70-114

43 Wyrtki K. Indonesian Throughflow and the associated pressure gradient. J Geophys Res, 1987, 92: 12941-12946

44 Liu Y, Feng M, Church J, et al. Effect of Salinity on Estimating Geostrophic Transport of the Indonesian Throughflow along the IX1 XBT Section. J Oceanogr, 2005, 61: 795-801

45 Fang G H, Susanto R D, Wirasantosa S, et al. Volume, heat, and freshwater transports from the South China Sea to Indonesian seas in the boreal winter of 2007-2008. J Geophys Res, 2010, 115: C12020

46 Clarke A J, Liu X. Observations and dynamics of semi-annual and annual sea levels near the eastern equatorial Indian Ocean boundary. J Phys Oceanogr, 1993, 23: 386-399

Open Access This article is distributed under the terms of the Creative Commons Attribution License which permits any use, distribution, and reproduction in any medium, provided the original author(s) and source are credited. 